actually form half the total annual cost of the system. However, the cost of installing the duct and cables, the cost of the lighting standard and fixture, and some of the costs of maintenance, such as cleaning and repair to equipment, increase but little for the larger sizes of lamps as compared with smaller. There is consequently a distinct economy in cost per unit of light in adopting the larger lamp sizes. For example, in the case of a series underground supply to an ornamental lighting system, the annual cost of a 1000-c. p. lamp is only of the order of twice that of a 250-c. p. lamp even though the larger lamp supplies four times as much light.

In view of the insufficiency of municipal appropriations it became quite common several years ago for individual groups of property holders to install sections of improved street lighting with ornamental equipment at private expense. However, because of the difficulty of insuring a continuance of proper maintenance under this plan, and also because of the recognition of the importance of this lighting as a municipal improvement, present practise is very distinctly in the direction of having the city handle contracts for the installation and operation of all street lighting. Particularly in business districts the city may assume the entire cost of the system in view of the benefits accruing to the city as a whole. In other cases, a large part of the cost of special lighting may be charged back to abutting property under the laws in many states which permit the establishment of special improved districts in which assessments are made for the street lighting in the same manner as for the paving and other necessary street improvements.

\section{CROSSING BEACONS}

BY L. C. PORTER

In the days of the horse-drawn vehicle a simple danger sign sometimes supplemented by a bell furnished adequate warning at dangerous crossings, such as railroad grade crossings, etc.

Today with the enclosed automobile limousine traveling at much greater speed than the horse and with many other trucks and cars having relatively noisy engines, the sign and bell are inadequate. Crossing gates and a watchman with a flag are improvements, but even that does not give a warning that has a punch to it; one that causes an approaching driver to sit up and take notice.

Signals that will accomplish this have been developed by using a flashing light in back of a red lens. Numerous tests have proved that a flashing light is very much more effective as a warning than a light burning steadily. The first general application of such warning beacons were to highway crossings, where the municipality could not afford a traffic officer. Later, they were used to supplement officers and in various other dangerous places. These beacons consisted of a flashing gas flame operating from a tank of compressed gas. Round diffusing globes were used and later lenses. The next application was to railroad grade crossings and here electric lamps operated from primary or storage batteries. The battery is placed underground and will operate the signal without any attention, for periods of one year or more. The lamps are made to outlast the battery and for assurance against burn-out are renewed when the battery is renewed.

As the small electric lamp used in this service (about 100-volt, 1/4-ampere) does not need the ventilation required by a gas flame, the lenses are being replaced by much more efficient parabolic reflectors, utilizing a slight percentage of the total light flux from the lamp. This combination projects a warning far down the road both by day and by night that is so conspicuous and so positive and reliable that it cannot be overlooked.

The effectiveness of these warning beacons is attested by the fact that the State of Massachusetts has permitted them to replace the gatemen at grade crossings.

For general use along the highways the warning light is also being used to illuminate route signs. A system of colors has been worked out to indicate whether the beacon is at a cross road, a turn, a dead end, etc. In many instances the beacons carry advertising material on the standard and lighted ads on the rear of its signal. Here devices are proving so effective and so popular that they will unquestionably, have a rapid growth throughout the country.

\section{A NEW USE FOR MINIATURE LAMPS}

Miniature lamps can be used to advantage for so many different purposes that seldom a day passes without some new use for them being discovered. Probably the very latest field of application found for these lamps is in lighting the thermometers in poultry incubators.

For several years incubator owners have realized that opening the incubators several times daily to read the thermometers was not the best thing in the world for the eggs. However, with most incubators this was the only way by which the temperature of the interior could be read accurately. Holding the flashlight or burning match outside the door-window to read the thermometer has always proved unsatisfactory - in many cases the glare from the glass window made the thermometer more difficult to read than without this light.

Several of the largest thermometer companies are now manufacturing electrically lighted thermometers for incubators, while some incubator manufacturers are using them in initial installations. The equipment consists of a thermometer equipped with a flashlight lamp, battery, and switch. The thermometer, lamp, and battery are installed inside the incubator, and the switch on the outside; when a reading is desired, it is necessary simply to close the circuit by means of this switch. With such an outfit the user will not lose a considerable amount of heat, and perhaps some of his chicks, every time he reads his incubator thermometer. 